\title{
Stimulatory effects of adenosine on prolactin secretion in the pituitary gland of the rat
}

D.L.W. Picanço-Diniz" M.M. Valença², A.L.V. Favaretto 3 and J. Antunes-Rodrigues ${ }^{3}$

\author{
1Departamento de Fisiologia, Centro de Ciências Biológicas, \\ Universidade Federal do Pará, Belém, PA, Brasil \\ 2Departamento de Neuropsiquiatria, Centro de Ciência da Saúde, \\ Universidade Federal de Pernambuco, Recife, PE, Brasil \\ ${ }^{3}$ Departamento de Fisiologia, Faculdade de Medicina de Ribeirão Preto, \\ Universidade de São Paulo, Ribeirão Preto, SP, Brasil
}

\section{Correspondence \\ J. Antunes-Rodrigues \\ Departamento de Fisiologia \\ FMRP, USP \\ Av. Bandeirantes, 3900 \\ 14049-900 Ribeirão Preto, SP \\ Brasil \\ E-mail: antunes@fmrp.usp.br}

Research supported by FAPESP (Nos. 91/0567-0 and 94/3805-7) and CNPq (Nos. 50167/91-7 and 521593/94-8).

Received August 29, 2001 Accepted May 7, 2002

\section{Abstract}

We investigated the effects of adenosine on prolactin (PRL) secretion from rat anterior pituitaries incubated in vitro. The administration of 5-N-methylcarboxamidoadenosine (MECA), an analog agonist that preferentially activates A2 receptors, induced a dose-dependent ( $1 \mathrm{nM}$ to $1 \mu \mathrm{M}$ ) increase in the levels of PRL released, an effect abolished by 1,3-dipropyl-7-methylxanthine, an antagonist of A2 adenosine receptors. In addition, the basal levels of PRL secretion were decreased by the blockade of cyclooxygenase or lipoxygenase pathways, with indomethacin and nordihydroguaiaretic acid (NDGA), respectively. The stimulatory effects of MECA on PRL secretion persisted even after the addition of indomethacin, but not of NDGA, to the medium. MECA was unable to stimulate PRL secretion in the presence of dopamine, the strongest inhibitor of PRL release that works by inducing a decrease in adenylyl cyclase activity. Furthermore, the addition of adenosine $(10 \mathrm{nM})$ mimicked the effects of MECA on PRL secretion, an effect that persisted regardless of the presence of $\mathrm{LiCl}(5 \mathrm{mM})$. The basal secretion of PRL was significatively reduced by $\mathrm{LiCl}$, and restored by the concomitant addition of both $\mathrm{LiCl}$ and myo-inositol. These results indicate that PRL secretion is under a multifactorial regulatory mechanism, with the participation of different enzymes, including adenylyl cyclase, inositol-1-phosphatase, cyclooxygenase, and lipoxygenase. However, the increase in PRL secretion observed in the lactotroph in response to A2 adenosine receptor activation probably was mediated by mechanisms involving regulation of adenylyl cyclase, independent of membrane phosphoinositide synthesis or cyclooxygenase activity and partially dependent on lipoxygenase arachidonic acid-derived substances.

\section{Introduction}

Adenosine is an endogenous nucleoside formed by the hydrolysis of adenosine 5'triphosphate (ATP) that modulates many physiological processes. In addition to the
- Adenosine

- Prolactin

- A2 receptor

- Pituitary gland
Key words well-known fundamental intracellular function exerted by ATP as the source of energy for living cells, several lines of evidence indicate that ATP is also released into the extracellular space. In this respect, the sympathetic nervous system releases the catechol- 
amines noradrenaline and adrenaline and the purines ATP, adenosine, and inosine. Concurrent release of ATP with other transmitters has been demonstrated. These include noradrenaline, substance P (1) and acetylcholine (2). Furthermore, in some nonneuronal cells ATP release could be carriermediated and may involve ATP-binding cassette proteins, a ubiquitous family of transport ATPases (3).

The membrane purinergic receptors are classified into $\mathrm{P} 1$ or adenosine receptors and P2 receptors, primarily recognizing ATP, adenosine 5'-diphosphate (ADP), uridine 5'diphosphate (UDP), and uridine 5'-triphosphate (UTP). Adenosine receptors have been further subdivided into four subtypes, A1, A2A, A2B, and A3, all of which couple to $G$ proteins. The $\mathrm{P} 2$ receptors are divided into two families of ligand-gated ion channels and $\mathrm{G}$ protein-coupled receptors termed $\mathrm{P} 2 \mathrm{X}$ and $\mathrm{P} 2 \mathrm{Y}$ receptors, respectively. Actually, seven mammalian $\mathrm{P} 2 \mathrm{X}$ receptors (P2X1-7) and five mammalian $\mathrm{P} 2 \mathrm{Y}$ receptors (P2Y1, P2Y2, P2Y4, P2Y6, P2Y11) have been cloned, characterized, and accepted as valid members of the $\mathrm{P} 2$ receptor family (4).

We have shown that dipyridamol, a blocker of adenosine transport, did not modify prolactin (PRL) secretion from hemipituitaries incubated in vitro, although it enhanced PRL stimulation induced by adenosine (5). These data demonstrated that a purinergic effect occurred mainly due to outer membrane receptors and that no effects of endogenous adenosine were observed in this type of in vitro preparation. Indeed, adenohypophyseal cell lines release adenosine together with the enzyme adenosine deaminase (6), suggesting that adenosine may act through an autocrine mechanism and that its levels may be regulated within strict limits.

Finally, adenosine analogues may have opposite effects on PRL secretion by modulating adenylyl cyclase activity (7), resulting in either an increase or a decrease in cyclic AMP levels in the lactotroph (8). These ef- fects may be related to the affinity of the receptor for different concentrations or structural groups of the agonist.

In the present study we investigated the activation of $\mathrm{A} 2$ receptors in the regulation of PRL secretion by the rat anterior pituitary gland in vitro. Interactions with dopamine as well as the involvement with adenylyl cyclase, inositol-1-phosphatase, cyclooxygenase, and lipoxygenase were investigated during purinergic stimulation of PRL secretion.

\section{Material and Methods}

Male Wistar rats weighing 200-220 g from the central Animal House of the Faculty of Medicine of Ribeirão Preto, University of São Paulo, were used. The animals were kept in collective cages in an artificially controlled environment with temperature ranging from 22 to $24^{\circ} \mathrm{C}$ on a 12-h light-dark cycle, with free access to solid food and water.

\section{Drugs and solutions}

The following drugs were used: $5-\mathrm{N}-$ methylcarboxamidoadenosine (MECA) and 1,3-dipropyl-7-methylxanthine (DPMX) (Research Biochemicals Incorporated, Natick, MA, USA); nordihydroguaiaretic acid (NDGA), indomethacin, bovine albumin, Earle salt solution and HEPES (Sigma, St. Louis, MO, USA); LiCl and ascorbic acid (Merck S.A. Indústrias Químicas, Rio de Janeiro, RJ, Brazil).

Nutrient solution consisted of Earle salt solution with $0.1 \%$ bovine albumin and 15 mM HEPES added, pH 7.4. Dopamine (10 $\mu \mathrm{M})$ was added with ascorbic acid $(100 \mu \mathrm{M})$ to the nutrient solution to prevent degradation.

\section{Experimental procedures}

After a period of adaptation of approximately $60 \mathrm{~min}$ to the laboratory, the animals were sacrificed by decapitation at 10:00 am for all experiments. The brain was removed 
and the anterior pituitary dissected in situ. The anterior pituitary was divided into two approximately equal parts and immersed in refrigerated nutrient solution $\left(4^{\circ} \mathrm{C}\right)$. Each hemipituitary was transferred to individual cuvettes containing $1.0 \mathrm{ml}$ nutrient solution $\left(37^{\circ} \mathrm{C}\right)$ and preincubated for $60 \mathrm{~min}$ in a Dubnoff water bath with constant shaking for washing and to stabilize basal hormonal secretion. The specific incubations were held immediately after a change of the nutrient solution used for preincubation. After incubation the samples were placed in plastic tubes at $-20^{\circ} \mathrm{C}$ and the hemipituitaries were weighed on a torsion scale. The values concerning the concentrations of PRL release into the nutrient solution were divided by the wet weight $(\mathrm{mg})$ of the hemipituitaries and reported as ng/mg tissue. At the end of each experiment, $56 \mathrm{mM} \mathrm{KCl}$ was added to evaluate the functional viability of cells on the basis of PRL release from intracellular stores. A considerable increase $(\mathrm{P}<0.001)$ in basal PRL secretion (337 $\pm 26 \mathrm{ng} / \mathrm{mg}$ tissue) was induced by the addition of $56 \mathrm{mM} \mathrm{KCl}(1,362$ $\pm 86 \mathrm{ng} / \mathrm{mg}$ tissue), indicating that the cells maintained their secretory response for more than 135 min of incubation, thus guaranteeing the viability of the tissue preparation. The basal value (control group) was obtained from hemipituitaries incubated with fresh medium.

\section{Radioimmunoassay}

PRL concentration in the nutrient solution was determined by double-antibody radioimmunoassay (RIA). The hormones for radioiodination and specific antibodies were obtained from the National Institute of Arthritis, Diabetes and Digestive Diseases (NADDK, Baltimore, MD, USA) Rat Pituitary Hormone Program.

\section{Statistical analysis}

Data are reported as means \pm SEM. Sta- tistical analysis was performed by analysis of variance (ANOVA) for all samples and by the unpaired Student $t$-test for comparison between groups, with the level of significance set at $\mathrm{P}<0.05$.

\section{Results}

\section{Effects of $\mathbf{A} 2$ receptor activation by MECA on basal PRL secretion}

The $\mathrm{A} 2$ adenosine receptor agonist MECA at the doses of 1 to $1,000 \mathrm{nM}$ induced a stimulatory dose-dependent effect on PRL secretion. The three-fold increase in PRL release reached a peak with $1,000 \mathrm{nM}$ MECA. The stimulatory potency of these effects of MECA were reduced at the dose of 10,000 nM (Figure 1).

Different doses of DPMX (10-1,000 nM), a selective adenosine A2 antagonist, had no effect on basal PRL secretion. The highest dose of DPMX used $(1,000 \mathrm{nM})$ caused total blockade of the effect of MECA on PRL release (Figure 2).

\section{Effects of MECA administration on PRL secretion inhibited by dopamine}

Administration of $10 \mu \mathrm{M}$ dopamine induced a significant decrease in the amount of PRL released into the incubation medium. None of the different MECA doses (1-1,000 $\mathrm{nM}$ ) administered after 15 min of preincuba-

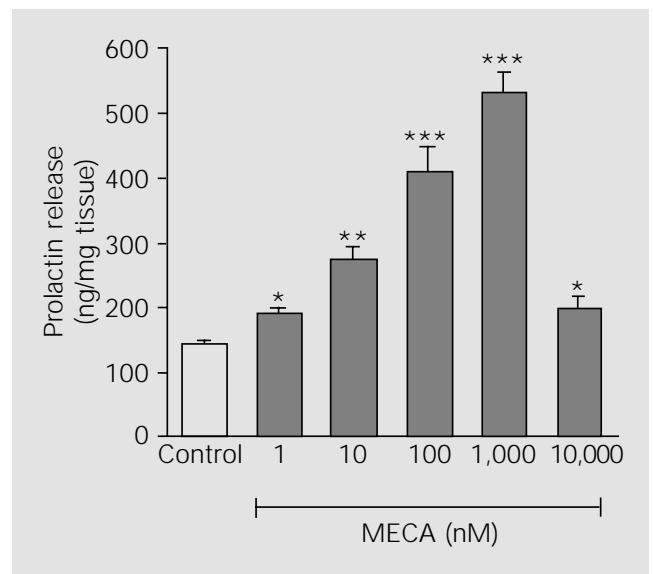

Figure 1. Effect of 5-N-methylcarboxamidoadenosine (MECA) on basal prolactin secretion. Data are reported as means \pm SEM $(\mathrm{N}=5) . \quad * \mathrm{P}<0.05$, $* * \mathrm{P}<0.01, * * * \mathrm{P}<0.001 \mathrm{com}$ pared to control (Student t-test). 
Figure 2. Effect of previous administration (30 $\mathrm{min}$ ) of 1,3-dipropyl-7-methylxanthine (DPMX), an $\mathrm{A} 2$ adenosine antagonist, on basal or $10 \mathrm{nM} 5-\mathrm{N}$-methylcarboxamidoadenosine (MECA)-induced prolactin secretion. Data are reported as means \pm SEM ( $N$ $=5)$. $* \mathrm{P}<0.05$ compared to control (Student t-test).
Figure 3. Effect of 5-N-methylcarboxamidoadenosine (MECA) in combination with $10 \mu \mathrm{M}$ dopamine on prolactin secretion. Data are reported as means \pm SEM $(\mathrm{N}=5)$. *P<0.01 compared to control (Student t-test).
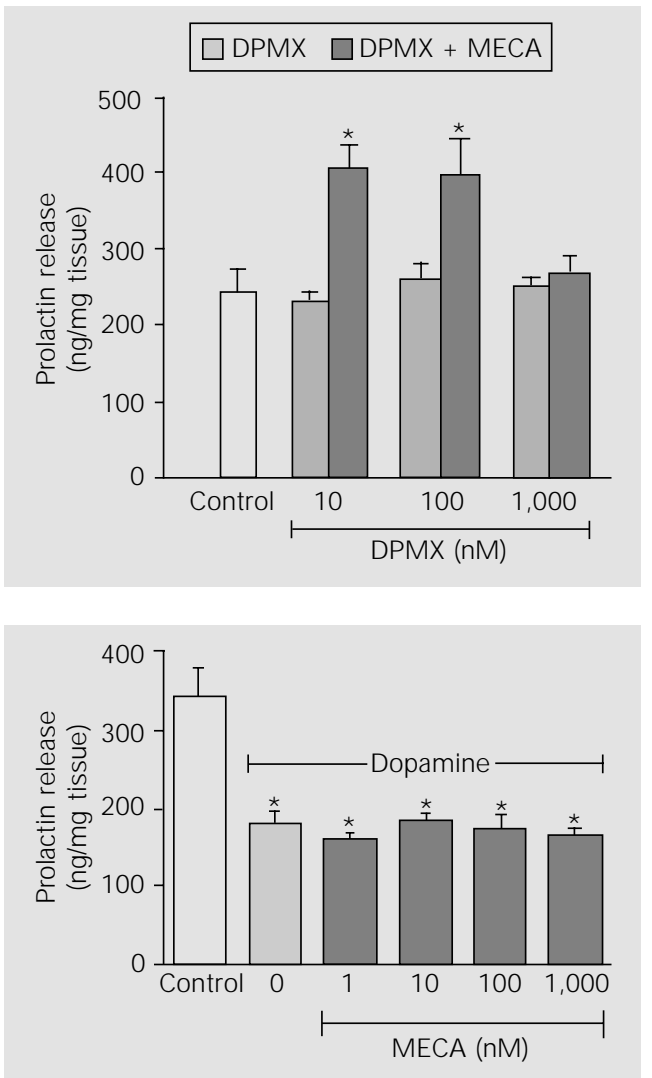

Figure 4. Effect of the administration of $5 \mathrm{mM} \mathrm{LiCl}$ or $10 \mathrm{nM}$ adenosine (Ado) and their combination on prolactin secretion. Addition of $1 \mathrm{mM}$ myo-inositol (Inos) alone or in combination with $5 \mathrm{mM} \mathrm{LiCl}$ was performed to test specificity of $\mathrm{LiCl}$ blocking effects. Data are reported as means \pm SEM $(\mathrm{N}=5) . * \mathrm{P}<0.05$ compared to control, $+\mathrm{P}<0.05$ compared to control LiCl (Student t-test).

Figure 5. Effect of $10 \mu \mathrm{M}$ indomethacin (Indo) or $10 \mu \mathrm{M}$ nordihydroguaiaretic acid (NDGA) on prolactin secretion. Data are reported as means \pm SEM ( $\mathrm{N}=$ 5). $* P<0.001$ compared to control (Student t-test).
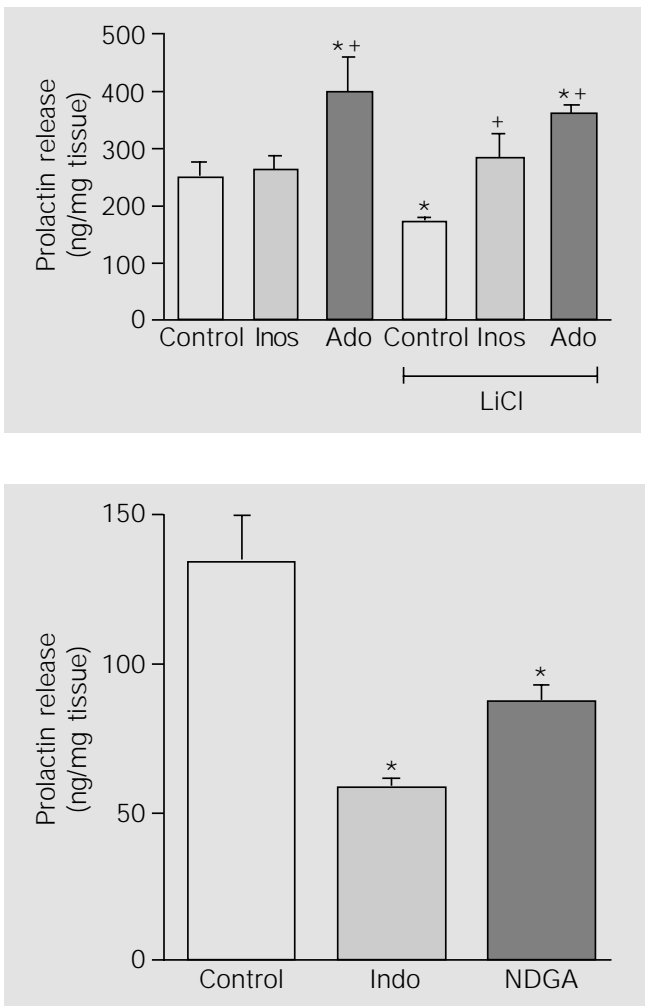

tion with $10 \mu \mathrm{M}$ dopamine modified the PRL inhibition induced by dopamine (Figure 3 ).

\section{Effects of adenosine administration on the secretion of PRL inhibited by LiCl}

In order to determine whether membrane phosphoinositide synthesis interfered with basal or adenosine-induced PRL secretion, 5 $\mathrm{mM} \mathrm{LiCl} \mathrm{(a} \mathrm{blocker} \mathrm{of} \mathrm{inositol-1-phos-}$ phatase) was added alone or in combination with $10 \mathrm{nM}$ adenosine to the nutrient solution. $\mathrm{LiCl}$ induced a significant decrease in basal PRL secretion. Adenosine caused a two-fold increase in basal PRL secretion, an effect not modified by combination with $\mathrm{LiCl}$ (Figure 4). In turn, $1 \mathrm{mM}$ myo-inositol did not change basal PRL secretion. However, myo-inositol stimulated PRL release in the presence of $\mathrm{LiCl}$, bringing it back to the normal control level.

\section{Effects of MECA administration on the secretion of PRL inhibited by indomethacin and NDGA}

In this experiment we used indomethacin and NDGA, which inhibit cyclooxygenase and lipoxygenase activities, respectively. Both, $10 \mu \mathrm{M}$ indomethacin and $10 \mu \mathrm{M}$ NDGA induced a significant reduction in basal PRL levels (Figure 5). MECA (10 nM) induced an increase in PRL release both under basal conditions and in the presence of indomethacin, being ineffective in the presence of NDGA (Figure 6).

\section{Discussion}

Activation of A2 purinoceptors induced PRL release from hemipituitaries incubated in vitro, an effect inhibited by lipoxygenase but not cyclooxygenase blockade. Inhibition of the enzyme inositol-1-phosphatase also did not alter the stimulatory effect of adenosine on PRL secretion. In addition, the inhib- 
itory effect of dopamine on PRL release was not counteracted by $\mathrm{A} 2$ receptor activation. This suggests that the A2 receptor mainly activates adenylyl cyclase, with some dependence on lipoxygenase activity.

These data are supported by the fact that adenosine analogues had stimulatory or inhibitory effects on adenylyl cyclase activity in preparations of adenohypophyseal cells in culture (7). In fact, in these preparations MECA induced a dose-dependent increase in adenylyl cyclase activity, confirming preferential activation of $\mathrm{A} 2$ receptor. If we extrapolate this information to our results, we infer that both $\mathrm{A} 1$ and $\mathrm{A} 2$ receptors occur in the lactotroph since the biphasic effect on PRL secretion was observed at MECA doses of 1 to $10 \mu \mathrm{M}$. Recent studies have demonstrated an increase in PRL after administration of an A1 agonist (9) or A2A agonist and a decrease in PRL secretion after administration of an A1 agonist in vitro (10). These apparently contradictory results suggest that the differences may depend on the presence or absence of adenosine in the preparation and/or the type of agonist administered. If we consider the possibility that the activation of dopamine receptors (D2) in the adenohypophysis modulated membrane $\mathrm{PG}_{\mathrm{i}}$ $(11,12)$ and inhibited adenylyl cyclase (13), we can infer that the activation of A2 receptors induced by MECA depends on the availability of $\mathrm{PG}_{\mathrm{s}}$, which may be blocked by $\mathrm{D} 2$ activation.
Independently of purinergic PRL control, eicosanoids seem to be involved in the regulatory mechanisms of PRL secretion, since the inhibition of $\mathrm{PG}$ and thromboxane synthesis by indomethacin and of leukotrienes and hydroxyeicosatetraenoic acid by NDGA resulted in a reduction in basal PRL release. These data confirm similar effects obtained by other investigators $(14,15)$.

Lithium (administered as $\mathrm{LiCl}$ ) inhibits the hydrolysis of L- and B-myo-inositol-1phosphate by the enzyme inositol-1-phosphatase, reducing the supply of myo-inositol for the cycle of membrane phosphoinositide synthesis in the cell (16). The administration of $5 \mathrm{mM} \mathrm{LiCl}$ inhibited basal PRL secretion. Its addition in combination with adenosine did not prevent the increase in PRL secretion induced by the nucleoside, suggesting that this effect does not depend on the intracellular levels of membrane phosphoinositides.

Another question is: What is the origin of adenosine at the pituitary interstitial level? We can postulate four different sources: a) from the systemic circulation, b) locally released, c) from nerve terminals in the median eminence into the portal-hypophyseal blood, and d) from direct innervation of the sympathetic nervous system of brain origin or partly originating in the superior cervical ganglia (17).

The superior cervical ganglia provide sympathetic innervation to several cephalic regions, such as pineal gland, blood vessels

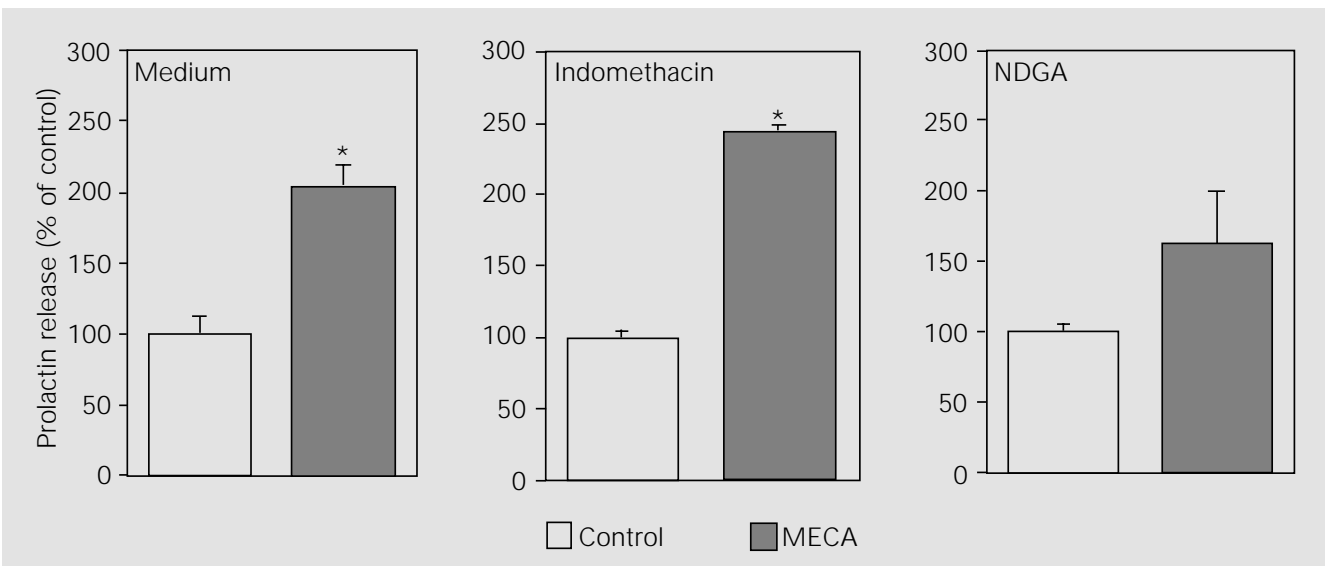

Figure 6. Effect of $25 \mathrm{nM} 5-\mathrm{N}$ methylcarboxamidoadenosine (MECA) on prolactin release in the absence or presence of 10 $\mu \mathrm{M}$ indomethacin or $10 \mu \mathrm{M}$ nordihydroguaiaretic acid (NDGA). Data are reported as means \pm SEM $(\mathrm{N}=5) .{ }^{*} \mathrm{P}<0.001 \mathrm{com}-$ pared to control (Student t-test). 
(including hypothalamic and pituitary gland), choroid plexus, carotid body, and salivary and thyroid glands. Cardinali et al. (18) proposed that the superior cervical ganglia can function as a peripheral neuroendocrine center. Tan and Ogawa (19) demonstrated that the sympathetic nervous system can play an important role in maintaining and regulating the secretory function of the adenohypophysis since superior cervical sympathetic ganglionectomy modified the hormonal secretory pattern.

Finally, these results provide suggestive evidence for a stimulatory action of adeno- sine on PRL secretion in a putative mechanism mediated by $\mathrm{A} 2$ receptors, partially dependent on cAMP synthesis and leukotrienes and possibly dissociated from the synthesis of membrane phosphoinositides and PG or thromboxanes.

\section{Acknowledgments}

We thank Rubens Fernando de Melo, Leonardo Fidelis Filho, Gilberto Lopes, Manoel Corrêa de Lima, Marina Holanda, and Maria Valci Aparecida dos Santos Silva for technical assistance.

\section{References}

1. Matsuka Y, Neubert J K, Maidment NT \& Spigelman I (2001). Concurrent release of ATP and substance $P$ within guinea pig trigeminal ganglia in vivo. Brain Research, 915: 248-255.

2. Schweitzer E (1987). Coordinated release of ATP and ACh from cholinergic synaptosomes and its inhibition by calmodulin antagonists. J ournal of Neuroscience, 7: 2948-2956.

3. Bodin P \& Bumstock $G$ (2001). Purinergic signalling: ATP release. Neurochemical Research, 26: 59-69.

4. Ralevic V \& Burnstock G (1998). Receptors for purines and pyrimidines. Pharmacological Reviews, 50: 413-492.

5. Picanço-Diniz DLW, Valença MM, Favaretto ALV \& Antunes-Rodrigues J (1992). Dipyridamole amplifies the effects of adenosine on gonadotropin and prolactin release from the rat anterior pituitary gland. Medical Science Research, 20: 783785.

6. Dorflinger LJ \& Schonbrunn A (1985). Adenosine inhibits prolactin and growth hormone secretion in a clonal pituitary cell line. Endocrinology, 117: 2330-2338.

7. Anand-Srivastava MB, Gutkowska J \& Cantin M (1985). Adenosine-sensitive adenylate cyclase in rat anterior pituitary. Neuroendocrinology, 41: 113-118.

8. Delahunty TM, Cronin MJ \& Linden J (1988). Regulation of $\mathrm{GH}_{3}$-cell function via adenosine $A_{1}$ receptors. Inhibition of pro- lactin release, cyclic AMP production and inositol phosphate generation. Biochemical J ournal, 255: 69-77.

9. Yu WH, Kimura M, Walczewska A, Porter J C \& McCann SM (1998). Adenosine acts by $A_{1}$ receptors to stimulate release of prolactin from anterior pituitaries in vitro. Proceedings of the National Academy of Sciences, USA, 95: 7795-7798.

10. Kumari M, Buckingham J C, Poyser RH \& Cover PO (1999). Roles for adenosine $A_{1^{-}}$ and $\mathrm{A}_{2}$-receptors in the control of thyrotrophin and prolactin release from the anterior pituitary gland. Regulatory Peptides, 79: 41-46.

11. Senogles SE, Benovic J L, Amlayk N, Unson C, Milligan G, Vinitsky R, Spielgel $M \&$ Caron MG (1987). The $D_{2}$ dopamine receptor of anterior pituitary is functionally associated with a pertussis toxin-sensitive guanine nucleotide. J oumal of Biological Chemistry, 262: 4860-4867.

12. Burris TP, Nguyen DN, Smith SG \& Freeman ME (1992). The stimulatory and inhibitory effects of dopamine on prolactin secretion involve different G-proteins. Endocrinology, 130: 926-932.

13. Enjalbert A \& Bockaert J (1983). Pharmacological characterization of $D_{2}$ dopamine receptor negatively coupled with adenylate cyclase in rat anterior pituitary. Molecular Pharmacology, 23: 576-584.

14. McCann SM, Rettori V, Milenkovic L, J urcovicova J \& Gonzalez MC (1990). Role of monokines in control of anterior pituitary hormone release. Advances in Experimental Medicine and Biology, 274: 315329.

15. Miyake A, Nishizaki T, Ikegami H, Koike $\mathrm{K}$, Hirota K \& Tanizawa O (1988). Possible involvement of lipoxygenase pathway of arachidonic acid in rat pituitary hormone release in vitro. J oumal of Endocrinological Investigation, 11 (Suppl 11): 805-808.

16. Hallcher LM \& Sherman WR (1980). The effects of lithium ion and other agents on the activity of myo-inositol-1-phosphatase from bovine brain. J oumal of Biological Chemistry, 25: 10896-10901.

17. Saavedra J M (1985). Central and peripheral catecholamine innervation of the rat intermediate and posterior pituitary lobes. Neuroendocrinology, 40: 281-284.

18. Cardinali DP, Vacas MI, Gejman PV, Pisarev MA, Barontini M, Boado RJ \& J uvenal GJ (1993). The sympathetic superior cervical ganglia as "little neuroendocrine brains". Acta Physiologica, Pharmacologica et Therapeutica Latinoamericana, 33: 205-221.

19. Tan $Y \& \&$ Ogawa H (1996). Effect of superior cenvical sympathetic ganglionectomy on FSH, LH and GH cells of hypophyseal gland in female rats: a quantitative immunohistochemical study. Masui, 45 (Suppl 10): 1223-1234. 